\title{
An Exploration of the Relation between Hunting and Aggressiveness: Using Inmates Networks at Prison Secondary School as an Illustration
}

\author{
Nikolaos Hasanagas, Alexandra Bekiari \\ Department of Physical Education and Sports Sciences, University of Thessaly, Trikala, Greece \\ Email: sandrab@pe.uth.gr
}

How to cite this paper: Hasanagas, N. and Bekiari, A. (2017) An Exploration of the Relation between Hunting and Aggressiveness: Using Inmates Networks at Prison Secondary School as an Illustration. Social Networking, 6, 19-37. http://dx.doi.org/10.4236/sn.2017.61002

Received: November 16, 2016

Accepted: December 18, 2016

Published: December 21, 2016

Copyright $\odot 2017$ by authors and Scientific Research Publishing Inc. This work is licensed under the Creative Commons Attribution International License (CC BY 4.0).

http://creativecommons.org/licenses/by/4.0/

(c) (i) Open Access

\begin{abstract}
Aim of this research is to explore the relation of hunting with aggressiveness. For this purpose, two samples of prison inmates (who were students of the prison secondary school) were collected (class $A=23$, class $B=12$ ). The network indicators for superficial, idiosyncratic and strategic behavior (particularly, aggressiveness), applied in Bekiari and Hasanagas (2016), which were based on the primary network variables (outdegree, indegree, Katz status, pagerank, authority) were used. Non-network variables were also used for the criminal profile of the inmates. The data were sampled with questionnaire. Spearman test was conducted for detecting correlation between aggressiveness and hunting and Principal Component Analysis was used for formulating a typology. The following results were produced: The criminal profile seems hardly to be related with hunting experience or attitude. The relation of hunting experience and attitude with the superficial, idiosyncratic and strategic aggressiveness was examined. These three occasions of aggressiveness are expected to describe the incidental reaction, impulsive and adaptive reaction, respectively. The hunting is quite irrelevant to the incidental reaction. The impulsiveness seems to be more strongly correlated with hunting. In case of adaptiveness, there are many similarities with impulsiveness. The typology which is based on the existence (or not) of hunting experience seems to be more insightful, as it reveals a gradual involvement of aggressiveness dimensions, from incidentality to impulsiveness and further to adaptiveness. The following behavioral patterns of gradually enhanced aggressiveness appear: incidentally just provoking, impulsively being aggressive but without harming, and adaptively being aggressive and harming.
\end{abstract}

\section{Keywords}

Hunting, Aggressiveness, Network Analysis, Prison Inmate School 


\section{Introduction}

The verbal aggressiveness has extensively been explored in various environments such as family, business organization and education system [1]-[8]. The impacts of the education-related verbal aggressiveness have been insightfully discussed focusing on motivation climate, attraction, satisfaction and learning [9]-[20]. The sport-related aggressiveness has also been extensively explored [20]-[27]. However, the afore-mentioned studies have mainly focused on the aggressiveness as a general educational and athletic concept and not specifically on the activity of hunting, which includes both educational and physical parameters (such ones are the collaboration and socialization with other hunters, the acquisition of technical, zoological and ecological knowledge, development of patience and persistence as well as of physical skills such as sharp vision and hearing, exercising in hits targeting, using gun and natural life). Additionally, the verbal aggressiveness seems to encourage the physical aggressiveness [28]. However, the aggressiveness occurring in the domestic education environment of the correctional system has not yet been extensively discussed, though it could provide insights into the deeper nature of the aggressiveness under conditions of suppression and/or oppression.

The relation of the susceptibility to aggressiveness with the possession and use of guns has also been extensively examined [29] [30]. Nevertheless, the relation of aggressiveness specifically with hunting was not insightfully discussed. [31] has tried an insightful approach to the relation of war, sport and aggression, suggesting, though, a comparison of theories and without strongly focusing on determinants or any particular typology of behavioral parameters and patterns.

[32] have provided a quite original and specific comparative analysis between hunters and non-hunters regarding the weapons effect. [33] has also provided an interesting approach to the phenomenon of the sky bust, which in part may be interpreted as an indicator of overflowing or immanent aggression. However, the deficit in deeper behavioral differences and intentions between these groups which may emerge under circumstances of suppression or oppression (such as imprisonment) still exists.

In any case, theorizing aggression and diagnosing aggressiveness is a matter of the operational definitions which are adopted and, subsequently, of the method used. Theorizing, operationalizing and measuring are closely interdependent. For this reason, the basic methodical concept of detecting, depicting and measuring aggressiveness should be discussed in this section.

Network analysis has already been used for measuring behavioral variables (including also aggression) and detecting relations between behavioral patterns as well as determinants of such behaviors [34]-[40]. Network analysis is based on the assumption that a behavior is not just a matter of individual tendencies and options but a structural phenomenon. As such one, it is calculated by network algorithms which detect the concentration of aggression either directly on a person or accumulatively from one person to another (chain of subsequent aggressive actions). It is also calculated to what extent a person is both attacking 
and attacked or only attacking. Thus, a person is not "aggressive" alone-as an autonomous and independent unit-but may be considered to be more or less aggressive depending on the actions he practiced to and received from the others. The whole of such behavioral relations constitutes a system of deep and possibly long-path interdependencies.

For the analysis of the primary network variables three indicators were used: a) the superficial, b) the idiosyncratic and c) the strategic behavior (particularly, aggressive behavior). These are expected to indicate incidental, impulsive and adaptive behavior, respectively, and have been suggested, theoretically supported and empirically tested in previous research [41]. The "superficial" aggression is just the percentage of aggressive actions from each person to the others to the whole actions (relations) constituting the aggressiveness network (outdegree). The so-called "idiosyncratic" aggression is the difference between the aggressive actions practiced by a person to the others and the aggressive actions he receives from them (indegree + Katz status + pagerank + authority) calculated either directly and superficially as first target (indegree-the inverted vertices of outdegree), or in accumulative forms (chains of successive actions), calculated with particular network algorithms such as Katz status, pagerank and authority [41]. (These network algorithms are not described in details here, as they are widely accessible in several articles and websites.)

As the difference expresses an increment (not a ratio), it is regarded as an indicator of immanent tendency of aggression, namely a tendency mainly dependent on the idiosyncrasy and not on the environment (the aggression received from the others). On the contrary, the "strategic" aggression is not the difference but the ratio of the afore-mentioned practiced and received aggression. This shows a reaction taking place proportionally to the environment and, thus, reveals a strategic behavioral pattern.

The expected academic added value of this research consists in:

-The distinctive and comparative exploration of these three forms of aggressiveness in a quantitative way (network analysis) in relation to hunting as well as the examination of the possible relation of network and non-network parameters of aggression, violence and deviant behavior to hunting.

-The typology seems to have not only descriptive but also explanatory value, as it seems to disclose not only distinguishable patterns of behavior depending on different occasions but also a gradual involvement of aggressiveness dimensions.

-The use of prison inmate school class as an illustration, which is supposed to externalize the maximum of possible aggression under the suppressive and/or oppressive conditions of imprisonment.

The practical added value is expected to consist in the detection of determinants of aggressiveness and of the formulation of a typology of aggressiveness, always focusing on hunting and non-hunting experience as well as on attitudes toward hunting. In this way, this study is expected to contribute to the general discussion about the possible relation between hunting and aggressiveness with 
this new basis of empirical evidences.

Aim of this research is to answer the following questions:

-To what extent the general criminal profile (including violent behavior) is related with hunting.

-To what extent aggressive behavior (superficial, idiosyncratic and strategic at four basic options of aggressive actions, namely threat, verbal, gestural harassment and harming) occurring within prison inmate network is correlated with hunting and non-hunting.

-To what extent these aggressive behavioral patterns appear as a reasonable typology (combinations) depending on the hunting-and no hunting familiarity.

\section{Method}

\subsection{Sampling}

In 2015, two network samples of male prison inmates were collected. Prison inmates were selected as sample for this research, because this sample provided the opportunity of clearer depicting possible relation of hunting with aggressiveness and deviant behavior in general. Male adult prisoners were preferred to female ones, as they are a typical and dominant category of prisoners. The practical difficulties mainly consisted in communication with prisoners of different education levels, trustfulness and interestedness in participating in such a research. These difficulties were effectively confronted with the help and mediation of prisoners who had gained the trust of others, who were of higher education level and of the prison school educators who explained to others the content of the questionnaire.

The particular prison was selected not randomly but because it was the only accessible opportunity. It was a demand of the inmates to keep secret not only their names but also the prison and even the country where the prison was located. The authors had to accept this commitment, as it was a prerequisite for the participation of the inmates in this research. The authors believe that even under these conditions (non randomness and full anonymity), the publication of this study makes sense, as it aims at providing information about correlations between behavioral patterns, attitudes and possible determinants of them, and to produce generalizable descriptive statistics for any particular country or social settings.

The samples consisted of two school classes (class $\mathrm{A}=23$ inmates and $\mathrm{B}=12$ inmates) functioning within the correctional facility in the framework of special adult education program, equivalent to secondary school level. The class A was composed of inmates 22 - 64 years old (average 36 ) and the class B of inmates 25 - 43 years old (average 33). In the class A, 11 of the 23 inmates declared that they were sentenced for violent actions while in class B, 3 out of 12 . Both classes were analyzed as a whole sample in order to gain more complete data concerning the prisoners' profiles. The comparison between the two classes was not a goal of this research.

Totally, 14 out of the 35 inmates were sentenced for crimes characterized by 
violence. In total, 13 inmates had finished the primary school, 18 the secondary school, 2 the high school and 1 inmate the higher education. In these samples of inmates a great variety of professions were to be found (i.e. technician, farmer, builder, carpenter, electrician, driver, blacksmith etc).

\subsection{Questionnaire}

The network-related part of questionnaire was to certain extent based on previous research [42]. Additionally, this part was completed with approaches of [43] [44] [45] concerning the analysis of social power. Thus, the questionnaire was enriched with more questions about aggressiveness (e.g. threat, harming).

The non-network part of the questionnaire was based on the afore-mentioned literature concerning hunting, criminality and correctional parameters and included the classical personal parameters (e.g. age, education, profession). Expert interview was also conducted with correctional and prison education staff. This interview was also of decisive importance for the final formulation of the questionnaire.

\subsection{Process}

The primary network variables (outdegree, indegree, Katz status, pagerank, authority) were calculated with Visone 1.1. The secondary network variables were calculated with SPSS 16. The correlation (Spearman test) between network and non-network variables for detecting determinants or effects and the Principal Component Analysis between network variables for formulating typology have also been conducted with SPSS 16.

Spearman test is preferred to multivariate analysis, as it provides a good overview on all possible relations making the effects comparable. Both this bivariate test and the Principal Component Analysis have been used for similar analysis in previous research [34] [37] [38] [39].

\section{Results}

Although the aim of this research was not to provide descriptive statistic, the following basic descriptive results are presented, in order to give a general description of the sample. From the total group of 35 inmates, 4 had been legal hunters, 5 illegal hunters, 6 had hunted sometimes legally and some other times illegally and 20 had never hunted. Concerning their attitudes towards hunting, 16 consider it to be something "brutal" and 17 do not see it negatively.

In Figure 1, the networks of the four kind of aggressiveness relations (threat, verbal and gestural harassment, and harming) are presented in circle form. Their structure (hierarchy) is indicatively analyzed with Katz status algorithm.

It is noticeable that the densest networks appear in class A $(7.3 \%-0.6 \%)$ and the least dense (with considerable difference) in class B $(1.9 \%-0.3 \%)$. This is evidence that this adult education program may have a remarkable impact on the social behavior of the inmates, as in the progress of time the density of aggressiveness is minimized. Thus, the learning effect of this program seems to 


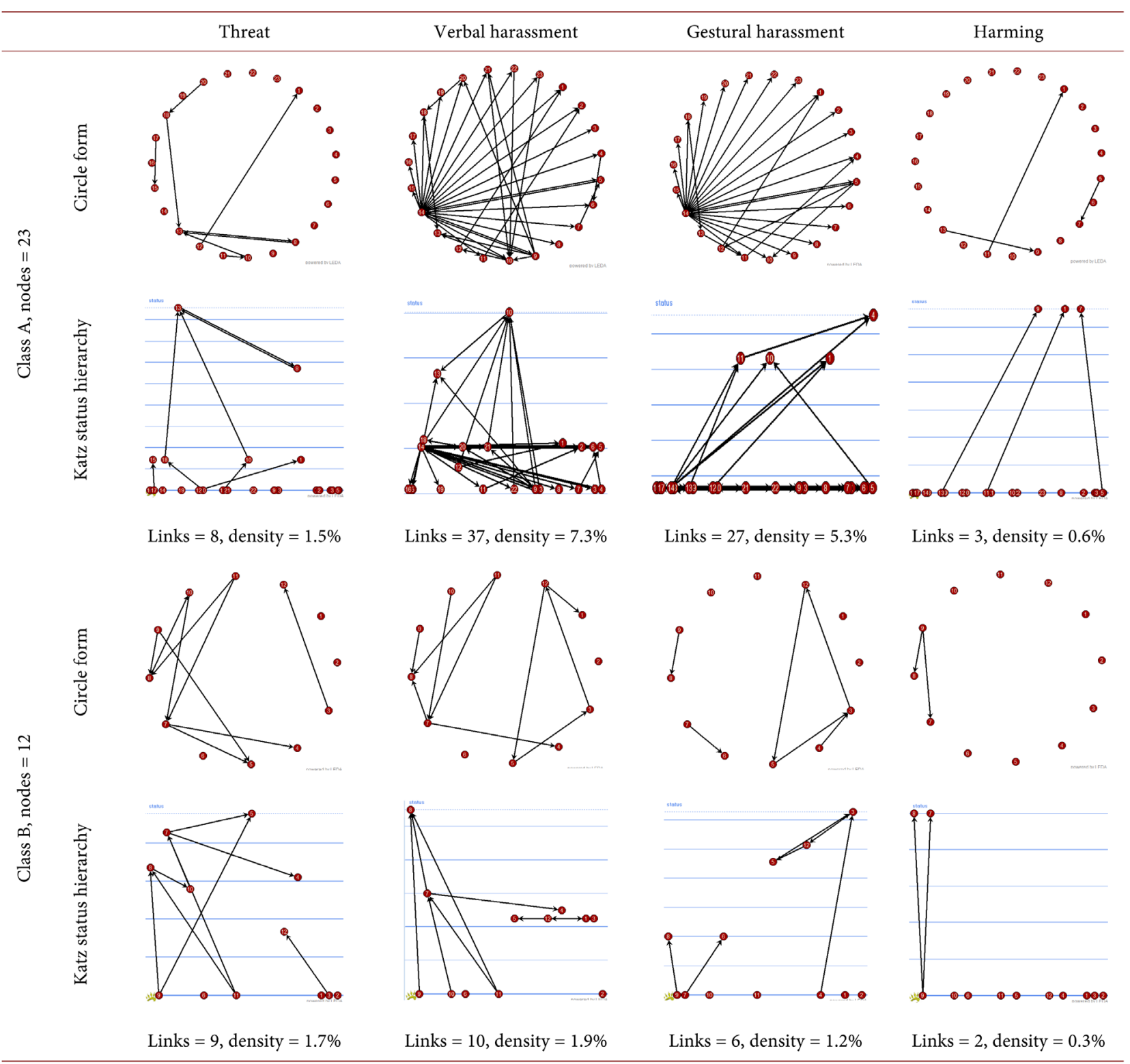

Figure 1. Example of the inmate networks.

consist in socialization.

The densest network (density $=$ proportion of existent relations to whole possible relations) is this of verbal harassment (7.3\% and $1.9 \%$ in class $\mathrm{A}$ and $\mathrm{B}$, respectively), as this is easiest way of clearly expressing aggressive disposition and clarify position towards thirds, aiming at their discouragement. The networks of gestural harassment come second in density (at least in class A). This can be attributed to the fact that this is a silent and symbolic way to communicate aggressiveness, and, thereby, not so clear, and, thereby, effective in expressing arguments or in discouraging thirds.

The networks of threat and harming are characterized by quite low density. This is understandable, considering the fact that this kind of aggressive communication is quite extreme and necessitates high aggressiveness or decidedness. 


\subsection{Hunting Parameters and Criminal Profile}

In Table 1, the relation of several aggressiveness parameters characterizing the personal life of prison inmates with hunting action and hunting-related attitudes is examined. Having been or not a legal hunter does not seem to be significantly correlated with any personal life characteristic.

Table 1. Hunting and criminal profile (non-network parameters of aggressiveness).

\begin{tabular}{|c|c|c|c|c|c|c|c|c|}
\hline & \multicolumn{3}{|c|}{ Hunting experience } & \multicolumn{5}{|c|}{ Attitude toward hunting } \\
\hline & $\begin{array}{c}\text { Have not } \\
\text { hunted at all }\end{array}$ & $\begin{array}{l}\text { Have hunted } \\
\text { legally }\end{array}$ & $\begin{array}{l}\text { Have hunted } \\
\text { illegally }\end{array}$ & $\begin{array}{l}\text { Hunting } \\
\text { is brutal }\end{array}$ & $\begin{array}{l}\text { Hunting } \\
\text { is a hobby }\end{array}$ & $\begin{array}{l}\text { Hunting } \\
\text { is a way } \\
\text { of life }\end{array}$ & $\begin{array}{l}\text { Encourage } \\
\text { my son } \\
\text { to hunt }\end{array}$ & $\begin{array}{l}\text { Encourage } \\
\text { my daughter } \\
\text { to hunt }\end{array}$ \\
\hline \multirow[t]{2}{*}{ Convicted for violent crime } & -0.118 & 0.073 & 0.093 & $0.394\left(^{*}\right)$ & -0.216 & 0.210 & 0.075 & 0.176 \\
\hline & 0.500 & 0.676 & 0.596 & 0.023 & 0.290 & 0.226 & 0.667 & 0.312 \\
\hline \multirow[t]{2}{*}{$\begin{array}{l}\text { Committed a crime under } \\
\text { angry circumstance }\end{array}$} & -0.306 & 0.110 & -0.186 & 0.266 & -0.281 & $0.420(*)$ & 0.251 & $0.546(* *)$ \\
\hline & 0.073 & 0.529 & 0.286 & 0.134 & 0.165 & 0.012 & 0.145 & 0.001 \\
\hline \multirow[t]{2}{*}{$\begin{array}{l}\text { Committed a crime } \\
\text { on purpose }\end{array}$} & -0.147 & -0.110 & $0.402\left(^{*}\right)$ & -0.096 & 0.133 & -0.053 & 0.013 & -0.125 \\
\hline & 0.398 & 0.529 & 0.017 & 0.596 & 0.516 & 0.764 & 0.943 & 0.475 \\
\hline \multirow[t]{2}{*}{$\begin{array}{l}\text { Committed a crime } \\
\text { using a fire gun }\end{array}$} & -0.198 & -0.062 & $0.377\left(^{*}\right)$ & 0.182 & . & -0.029 & -0.116 & -0.070 \\
\hline & 0.254 & 0.725 & 0.026 & 0.310 & . & 0.867 & 0.507 & 0.690 \\
\hline \multirow[t]{2}{*}{$\begin{array}{l}\text { Committed a crime } \\
\text { using a truncheon }\end{array}$} & -0.284 & -0.088 & $0.541\left(^{* *}\right)$ & 0.008 & 0.133 & -0.042 & -0.167 & -0.100 \\
\hline & 0.098 & 0.613 & 0.001 & 0.966 & 0.516 & 0.810 & 0.339 & 0.566 \\
\hline \multirow[t]{2}{*}{$\begin{array}{l}\text { Committed a crime using } \\
\text { other tool (incl. axe) }\end{array}$} & -0.147 & -0.110 & $0.402\left(^{*}\right)$ & 0.115 & 0.133 & -0.053 & -0.207 & -0.125 \\
\hline & 0.398 & 0.529 & 0.017 & 0.524 & 0.516 & 0.764 & 0.232 & 0.475 \\
\hline \multirow[t]{2}{*}{ Committed theft } & -0.091 & -0.028 & $0.384\left(^{*}\right)$ & -0.112 & 0.264 & -0.108 & -0.292 & -0.258 \\
\hline & 0.602 & 0.871 & 0.023 & 0.535 & 0.193 & 0.535 & 0.089 & 0.135 \\
\hline \multirow[t]{2}{*}{ Committed cyber crime } & -0.198 & -0.062 & $0.377(*)$ & -0.171 & 0.133 & -0.029 & -0.116 & -0.070 \\
\hline & 0.254 & 0.725 & 0.026 & 0.340 & 0.516 & 0.867 & 0.507 & 0.690 \\
\hline \multirow[t]{2}{*}{$\begin{array}{l}\text { Committed other crime } \\
\text { (incl. domestic violence) }\end{array}$} & -0.151 & 0.200 & 0.079 & $0.442\left(^{*}\right)$ & -0.178 & -0.101 & -0.117 & -0.059 \\
\hline & 0.387 & 0.250 & 0.651 & 0.010 & 0.385 & 0.564 & 0.504 & 0.738 \\
\hline \multirow[t]{2}{*}{$\begin{array}{l}\text { Severity of criminal behavior } \\
\text { (years of sentence) }\end{array}$} & -0.021 & -0.051 & -0.051 & -0.217 & 0.062 & -0.124 & 0.061 & 0.041 \\
\hline & 0.905 & 0.773 & 0.774 & 0.232 & 0.769 & 0.483 & 0.732 & 0.820 \\
\hline \multirow[t]{2}{*}{$\begin{array}{l}\text { General relapsing } \\
\text { (previous times of imprisonment) }\end{array}$} & -0.012 & -0.157 & 0.314 & -0.116 & 0.142 & -0.173 & -0.137 & -0.297 \\
\hline & 0.944 & 0.367 & 0.067 & 0.521 & 0.488 & 0.321 & 0.432 & 0.083 \\
\hline \multirow[t]{2}{*}{$\begin{array}{c}\text { Specific relapsing } \\
\text { (convicted again for similar crime) }\end{array}$} & 0.189 & -0.147 & 0.031 & -0.072 & -0.020 & -0.070 & -0.101 & 0.060 \\
\hline & 0.278 & 0.401 & 0.860 & 0.692 & 0.922 & 0.689 & 0.566 & 0.733 \\
\hline
\end{tabular}

${ }^{* *}$ Correlation is significant at the 0.01 level (2-tailed); ${ }^{\star}$ Correlation is significant at the 0.05 level (2-tailed). 
Those who have hunted illegally ( 0.402 to 0.377 ) tend to commit premeditated crimes and to use a gun, truncheon or even axe. These weapons reveal all an intensive aggression, as the gun makes, even potentially, a severe injury and the truncheon (much more the axe) necessitates a remarkable decisiveness or angriness to attack to the target person having a close contact with him. Especially, attacking to a person from a close distance (as normally the case is with a truncheon or axe) is supposed to be a serious evidence of aggressiveness [46]. The use of gun for committing the crime may also be positively correlated with the (illegal) hunting as both can be attributed to abandon or susceptibility to deviant behavior and familiarity with firing. Attributing the illegal hunting to a generalized tendency to criminality is also supported by the finding that inmates having hunted illegally are also imprisoned for theft and cybercrime, which is not correlated with physical aggressiveness at all. The engagement with criminal behavior in terms of relapsing or the criminal severity in terms of penalty proves to be irrelevant to the hunting (legal or illegal).

Paradoxically, inmates who regard hunting as "brutal" seem to be susceptible to violence, as they tend to be convicted for violent crimes (0.394), which may even include domestic violence (0.442). This can be understood as a result of a negative attitude toward human beings which is outbalanced by a strong sympathy to the animals. Individuals who are disappointed by human beings possibly try to find emotional consolation in the animal genre.

It is noticeable that inmates who have committed a crime under angry circumstance tend to perceive hunting as a way of life (0.420) and not as a usual hobby and to be more susceptible to encourage potentially her daughter to become a hunter (0.546). This is in accordance with results of previous research [47] which supported that people who regard the hunting as a way of life seem to have adopted life-defining values, such as dominance, leadership, development of personality and skills or general effectiveness. Such a value system makes someone intellectually or socially challengeable and seems to be deep-rooted enough to overcome gender-specific prejudices. As for the understanding of such a correlation (namely, between perceiving hunting as a way of life and committing a crime by angriness), it could be reasonably supposed that people, who search for a world view, are dedicated to an "ideal" (even individualized "ideals"). Thus, they are quite sensitive to any offense of these "ideals" and they become respectively angry enough to try to restore their "hart" worldview, even by committing a crime. Namely, people who seek the "perfect" world, even according to their subjective criteria, are intolerant to any "imperfection". This intolerance stimulates them to commit a crime. In other word, they become criminals because they are romantic and perfectionists. Such people tend also to maintain a perfectionist and romantic world view, and thereby, to perceive also hunting as a way of life.

It is also remarkable that though regarding hunting as a way of life (deeprooted value system) is significantly correlated with committing crime by angriness, it is not strongly correlated with violent criminality (0.210 insign.). This 
constitutes an evidence that such a deep consideration of hunting derives from (and/or is confined to) a "romantic" world view and does not find any deeper integration into what could be characterized as "underworld" or "organized criminality".

Relapsing and severity are not significantly correlated with any hunting-related experience or attitude. This is understandable, as these parameters of criminal behavior are rather related with external (and accidental) circumstances and not to internal determinants (values, world view, idiosyncrasy) which influence the relation of a person to hunting. Thereby, it is also obvious that hunting is not correlated with any destructive behavior which leads up to marginalization and unsocial options of life.

Finally, perceiving hunting as a hobby is not significantly correlated with any parameter of criminality. This is reasonable, as "hobby" is a quite neutral notion which is mainly related with entertainment and not with any idiosyncratic feature.

\subsection{Hunting Parameters and Profile of Aggressiveness}

In Table 2, the superficial aggressiveness seems hardly to be correlated with any hunting experience or attitude toward hunting, as almost all coefficients are insignificant. Neither general threat, nor verbal harassment, nor even gestural harassment appears to be relevant to any previous experience with hunting or any attitude toward this. This is understandable, considering the fact that the superficial aggressiveness is quite incidental. Such incidental behavioral patterns are rather accidental than deep-rooted to the value system of the individuals. Thereby, superficial aggressiveness can hardly be related with any attitude toward free time activities demanding in time, energy and money or characterized by specific values, such as hunting.

Only the superficial harming seems to be positively correlated (0.365) with encouraging his daughter to become a hunter. This seems to be indirectly in ac-

Table 2. Hunting and superficial aggressiveness.

\begin{tabular}{|c|c|c|c|c|c|c|c|c|}
\hline & \multicolumn{3}{|c|}{ Hunting experience } & \multicolumn{5}{|c|}{ Attitude toward hunting } \\
\hline & $\begin{array}{c}\text { Have not } \\
\text { hunted } \\
\text { at all }\end{array}$ & $\begin{array}{c}\text { Have } \\
\text { hunted } \\
\text { legally }\end{array}$ & $\begin{array}{c}\text { Have } \\
\text { hunted } \\
\text { illegally }\end{array}$ & $\begin{array}{l}\text { Hunting } \\
\text { is brutal }\end{array}$ & $\begin{array}{l}\text { Hunting } \\
\text { is a hobby }\end{array}$ & $\begin{array}{l}\text { Hunting } \\
\text { is a way } \\
\text { of life }\end{array}$ & $\begin{array}{c}\text { Encourage } \\
\text { my son } \\
\text { to hunt }\end{array}$ & $\begin{array}{c}\text { Encourage } \\
\text { my daughter } \\
\text { to hunt }\end{array}$ \\
\hline \multirow[t]{2}{*}{ Superficial threat } & 0.078 & 0.071 & -0.209 & -0.073 & -0.064 & -0.135 & 0.111 & 0.040 \\
\hline & 0.656 & 0.686 & 0.227 & 0.688 & 0.757 & 0.438 & 0.526 & 0.820 \\
\hline \multirow[t]{2}{*}{ Superficial verbal harassment } & -0.157 & 0.127 & 0.099 & -0.133 & -0.110 & -0.179 & -0.042 & -0.049 \\
\hline & 0.368 & 0.468 & 0.571 & 0.462 & 0.594 & 0.303 & 0.811 & 0.778 \\
\hline \multirow[t]{2}{*}{ Superficial gestural harassment } & -0.275 & -0.047 & 0.321 & -0.297 & 0.153 & -0.121 & 0.000 & 0.020 \\
\hline & 0.110 & 0.787 & 0.060 & 0.093 & 0.454 & 0.489 & 10.000 & 0.911 \\
\hline Superficial harming & 0.168 & 0.309 & 0.081 & 10.000 & 0.347 & 0.726 & 0.375 & 0.031 \\
\hline
\end{tabular}

${ }^{* *}$ Correlation is significant at the 0.01 level (2-tailed); ${ }^{*}$ Correlation is significant at the 0.05 level (2-tailed). 
cordance with the result of the previous Table 1, revealing the possible existence of a dominance-related world view embodied in hunting idea according to the feeling of inmates who have committed crime under angry circumstance. Such a world view appears to be strong enough to overcome gender-specific trends. It is also strong enough to overcome hesitations and, thus, to direct someone to harmful behavior.

In Table 3, the idiosyncratic aggressiveness seems to be more sensitive than the superficial aggressiveness (Table 2), as it is significantly correlated with more parameters of hunting experience or attitude. The tendency of over-extrovert threat deriving from the individual idiosyncrasy is negatively correlated $(-0.343)$ with illegal hunting. This is understandable, as someone who is involved in illegal and threatening way of life is natural to avoid illegal hunting because he tries to avoid arrest and further implications or because he does not have any time to spend in such an illegal activity which is quite little profitable and simultaneously quite risky for implications.

Inmates who are gestural insulting to others have tended to avoid the absolute keeping out of hunting $(-0.393)$. This can be attributed to the fact that such persons maintain a latent but and "mild" (not very disturbing or harmful) way for discharging their aggressiveness. Thus, individuals who adopt such a way to express their aggressiveness in their everyday life do not exclude physical discharging ways like hunting. In other words, they use the gestural behavior as a symbolic way of externalizing an immanent and possibly permanent aggressiveness, needing hunting as additional way to express aggressiveness. The symbolic and the physical way appear, thereby, to be quite interdependent or compatible, like two complementary world views.

The idiosyncratic harmful behavior appears to be strongly related with the neutral perception of hunting as a simple "hobby" (0.479) without any deep-

Table 3. Hunting and idiosyncratic over-extrovert aggressiveness.

\begin{tabular}{|c|c|c|c|c|c|c|c|c|}
\hline & \multicolumn{3}{|c|}{ Hunting experience } & \multicolumn{5}{|c|}{ Attitude toward hunting } \\
\hline & $\begin{array}{c}\text { Have not } \\
\text { hunted } \\
\text { at all }\end{array}$ & $\begin{array}{l}\text { Have hunted } \\
\text { legally }\end{array}$ & $\begin{array}{l}\text { Have hunted } \\
\text { illegally }\end{array}$ & $\begin{array}{l}\text { Hunting is } \\
\text { brutal }\end{array}$ & $\begin{array}{c}\text { Hunting is a } \\
\text { hobby }\end{array}$ & $\begin{array}{c}\text { Hunting is a } \\
\text { way of life }\end{array}$ & $\begin{array}{c}\text { Encourage } \\
\text { my son to } \\
\text { hunt }\end{array}$ & $\begin{array}{c}\text { Encourage } \\
\text { my daughter } \\
\text { to hunt }\end{array}$ \\
\hline \multirow[t]{2}{*}{ Idiosyncratic over-extrovert threat } & 0.120 & 0.224 & $-0.343\left(^{*}\right)$ & -0.183 & 0.085 & -0.140 & 0.069 & 0.103 \\
\hline & 0.491 & 0.196 & 0.043 & 0.308 & 0.679 & 0.424 & 0.694 & 0.555 \\
\hline \multirow{2}{*}{$\begin{array}{l}\text { Idiosyncratic over-extrovert } \\
\text { verbal harassment }\end{array}$} & -0.224 & 0.125 & 0.038 & 0.026 & -0.306 & 0.026 & 0.031 & 0.088 \\
\hline & 0.196 & 0.474 & 0.830 & 0.888 & 0.128 & 0.884 & 0.861 & 0.614 \\
\hline \multirow[t]{2}{*}{$\begin{array}{l}\text { Idiosyncratic over-extrovert } \\
\text { gestural harassment }\end{array}$} & $-0.393(*)$ & 0.106 & 0.268 & -0.220 & 0.313 & 0.097 & 0.167 & 0.205 \\
\hline & 0.019 & 0.545 & 0.120 & 0.218 & 0.120 & 0.581 & 0.337 & 0.237 \\
\hline \multirow{2}{*}{$\begin{array}{c}\text { Idiosyncratic over-extrovert } \\
\text { harming }\end{array}$} & 0.028 & 0.181 & -0.008 & -0.188 & $0.479\left(^{*}\right)$ & -0.146 & 0.249 & 0.167 \\
\hline & 0.875 & 0.297 & 0.963 & 0.294 & 0.013 & 0.403 & 0.150 & 0.338 \\
\hline
\end{tabular}

${ }^{*}$ Correlation is significant at the 0.01 level (2-tailed); ${ }^{\star}$ Correlation is significant at the 0.05 level (2-tailed). 
rooted values or a certain normative character. This is understandable as the idiosyncrasy-induced harmfulness necessitates certain insensibility and independence of "constructive" values defining way of life or normative attitudes. Thus, the idiosyncratic harmful behavior seems to reveal or to be identified with immanent (not rational) aggressiveness.

As for the idiosyncratic verbal harassment, it seems to be independent of any hunting parameter (in sign. co-efficients). This can be attributed to the fact that verbal aggressiveness just consists of words while hunting constitutes an activity quite demanding in time, skills and technical means. Thus, impulsive verbal aggressiveness and hunting are obviously two behavioral patterns of absolutely different nature.

The results of Table 4 are partly in accordance with these of Table 3, as the strategic over-extrovert aggressiveness is also negatively correlated with illegal hunting $(-0.351)$ and positively correlated with perceiving hunting as a simple "hobby" (0.479). This similarity of the results between the idiosyncratic (Table 3 ) and the strategic over-extrovert aggressiveness (Table 4) in case of hunting-related profile of the inmates can be attributed to the fact that the immanent aggressiveness of the inmates detected in Table 3 still exists in the correctional facility and is converted into strategic behavior (namely, they adjust their aggressiveness in proportional relation to the aggressiveness they receive from the social environment of the prison).

Nevertheless, a difference between Table 3 and Table 4 appears in the case of gestural harassment ( -0.328 insign.) Such a form of (symbolic) aggressiveness seems to be quite sophisticated and impulsive. Thus, it can be detected only as an individualized idiosyncratic action and not as a strategic response to the environment.

Table 4. Hunting and strategic over-extrovert aggressiveness.

\begin{tabular}{|c|c|c|c|c|c|c|c|c|}
\hline & \multicolumn{3}{|c|}{ Hunting experience } & \multicolumn{5}{|c|}{ Attitude toward hunting } \\
\hline & $\begin{array}{c}\text { Have not } \\
\text { hunted at all }\end{array}$ & $\begin{array}{c}\text { Have huntec } \\
\text { legally }\end{array}$ & $\begin{array}{l}\text { Have hunted } \\
\text { illegally }\end{array}$ & $\begin{array}{l}\text { Hunting is } \\
\text { brutal }\end{array}$ & $\begin{array}{c}\text { Hunting is a } \\
\text { hobby }\end{array}$ & $\begin{array}{l}\text { Hunting is } \\
\text { a way of life }\end{array}$ & $\begin{array}{c}\text { Encourage my } \\
\text { son to hunt }\end{array}$ & $\begin{array}{l}\text { Encourage my } \\
\text { daughter to hunt }\end{array}$ \\
\hline \multirow[t]{2}{*}{ Strategic over-extrovert threat } & 0.203 & 0.151 & $-0.351\left(^{*}\right)$ & -0.150 & -0.006 & -0.192 & 0.088 & 0.019 \\
\hline & 0.243 & 0.387 & 0.039 & 0.404 & 0.978 & 0.269 & 0.616 & 0.913 \\
\hline \multirow[t]{2}{*}{$\begin{array}{l}\text { Strategic over-extrovert } \\
\text { verbal harassment }\end{array}$} & -0.184 & 0.170 & 0.045 & -0.013 & -0.206 & -0.060 & 0.037 & 0.059 \\
\hline & 0.291 & 0.330 & 0.796 & 0.944 & 0.313 & 0.733 & 0.834 & 0.737 \\
\hline \multirow[t]{2}{*}{$\begin{array}{l}\text { Strategic over-extrovert } \\
\text { gestural harassment }\end{array}$} & -0.328 & 0.069 & 0.245 & -0.293 & 0.199 & 0.061 & 0.123 & 0.195 \\
\hline & 0.054 & 0.694 & 0.157 & 0.098 & 0.330 & 0.726 & 0.482 & 0.262 \\
\hline \multirow[t]{2}{*}{$\begin{array}{c}\text { Strategic over-extrovert } \\
\text { harming }\end{array}$} & 0.028 & 0.181 & -0.008 & -0.188 & $0.479\left(^{*}\right)$ & -0.146 & 0.249 & 0.167 \\
\hline & 0.875 & 0.297 & 0.963 & 0.294 & 0.013 & 0.403 & 0.150 & 0.338 \\
\hline
\end{tabular}

${ }^{* *}$ Correlation is significant at the 0.01 level (2-tailed); ${ }^{*}$ Correlation is significant at the 0.05 level (2-tailed). 


\subsection{Hunting and Typology of Aggressiveness}

In the following tables, a hunting-related typology of aggressiveness is suggested. Both having hunted (legally or not) and no familiarity with hunting may allow developing different types (feature combinations) of aggressiveness. These are going to be compared and discussed.

Concerning the superficial aggressiveness (Table 5), the hunting-familiar group of inmates seems to constitute an appropriate milieu for the combination of verbal (0.989) and gestural (0.988) harassment (the "just provocative" type) and of threat (0.877) and harming (0.880) ("threatening and harmful" type). These types are complementary in sense that their sum is the whole of aggressiveness parameters (all four). Moreover, these types seem to be completely alternative to each other, as they include completely different aggressiveness parameters.

More precisely, a hunting-familiar inmate tends either just to "provoke" by announcing only an intention of aggressiveness (through verbal and gestural communication) without implementing this intention, or to implement aggressiveness in form of threat and harming without announcing their intention.

On the other hand, the group of inmates who are unfamiliar to hunting let also complementary but less clear types emerge. In other word, such an inmate tends in any case to harm other inmates in the prison. However, he tries to implement his harmfulness either in an unsophisticated way (manifested threatening and verbal harassment) or in a sophisticated one, namely through gestural communication, which causes much less noise and turbulence than direct threats or indiscrete verbal aggression.

In contrast to the hunting-familiar group, the behavioral patterns of huntingunfamiliar inmates still seem to be complementary but not absolutely alternative, as they include implementation of harmfulness in any case. Thus, the hunting-familiar inmates present a much clearer behavioral orientation than the hunting-unfamiliar inmates.

In Table 6, a typology of the idiosyncratic over-extrovert aggressiveness is depicted. It is noticeable that it is quite similar to the typology of the superficial aggressiveness described in Table 5, though it could be expected that the

Table 5. Superficial aggressiveness typology of inmates.

\begin{tabular}{|c|c|c|c|c|}
\hline & \multicolumn{2}{|c|}{ Hunting-familiar (=15 inmates) } & \multicolumn{2}{|c|}{ No hunting-familiar (=20 inmates) } \\
\hline & $\begin{array}{c}\text { Just provocative } \\
\text { (announcing without implementing) }\end{array}$ & $\begin{array}{l}\text { Threatening and harmful } \\
\text { (implementing without announcing) }\end{array}$ & $\begin{array}{l}\text { Unsophisticated } \\
\text { and harmful }\end{array}$ & $\begin{array}{l}\text { Sophisticated } \\
\text { and harmful }\end{array}$ \\
\hline Superficial threat & 0.020 & 0.877 & 0.863 & -0.050 \\
\hline $\begin{array}{l}\text { Superficial verbal } \\
\text { harassment }\end{array}$ & 0.989 & -0.029 & 0.788 & -0.435 \\
\hline $\begin{array}{l}\text { Superficial gestural } \\
\text { harassment }\end{array}$ & 0.988 & 0.010 & 0.296 & 0.390 \\
\hline Superficial harming & 0.001 & 0.880 & 0.325 & 0.832 \\
\hline
\end{tabular}

Extraction method: Principal component analysis. 
Table 6. Idiosyncratic aggressiveness typology of inmates.

\begin{tabular}{ccccc}
\hline & \multicolumn{2}{c}{ Hunting-familiar (=15 inmates) } & No hunting-familiar (=20 inmates) \\
\cline { 2 - 5 } & $\begin{array}{c}\text { Aggressive } \\
\text { but harmless }\end{array}$ & $\begin{array}{c}\text { Threatening and harmful } \\
\text { (implementing without announcing) }\end{array}$ & $\begin{array}{c}\text { Unsophisticated } \\
\text { and harmful }\end{array}$ & $\begin{array}{c}\text { Sophisticated } \\
\text { and harmful }\end{array}$ \\
\hline Idiosyncratic over-extrovert threat & 0.354 & 0.643 & 0.887 & -0.132 \\
Idiosyncratic over-extrovert verbal harassment & 0.956 & -0.221 & 0.842 & 0.041 \\
Idiosyncratic over-extrovert gestural harassment & $\mathbf{0 . 9 5 4}$ & -0.207 & -0.254 & 0.911 \\
Idiosyncratic over-extrovert harming & 0.235 & $\mathbf{0 . 7 6 6}$ & $\mathbf{0 . 6 5 8}$ & $\mathbf{0 . 4 7 8}$ \\
\hline
\end{tabular}

Extraction method: Principal component analysis.

idiosyncratic behavior might be quite different from superficial behavioral pataggressiveness described in Table 5, though it could be expected that the idiosyncratic behavior might be quite different from superficial behavioral patterns (which are supposed to depend on incidental conditions rather than on the personality of the inmates).

In the group of the inmates who are unfamiliar with hunting, the same two types seem to dominate: "unsophisticated and harmful" (.887, .842 and .658) and "sophisticated and harmful" ( 0.911 and 0.478$)$. This similarity between superficial and idiosyncratic reaction in case of hunting-unfamiliarity reveals behavioral profiles which could reasonably be regarded as quite common and stable. Persons who stably conserve harmfulness and may simply express it either indiscreetly or covertly do not search for an alternative way-like hunting-in order to convert their outburst into harmless aggressiveness. This is obviously an endogenous (idiosyncratic) harmfulness which inevitably appears as superficial behavior (Table 5).

The hunting-familiar group presents the profile of "threatening and harmful" type $(0.643$ and 0.766$)$. In other word, as expected, the underhandedness is not only incidentally but also endogenously induced. This furtively harmful side of the idiosyncrasy is also immanent in the hunting-familiar group. Thus, hunting does not seem to constitute a drastic way of releasing such tendencies or of ethical "salvation".

The noticeable difference between superficial (Table 5) and idiosyncratic aggressiveness (Table 6) appears in the hunting-familiar group between the "just provocative" and the "aggressive and harmful" type. The "aggressive and harmful" type $(0.354,0.956,0.954)$ additionally includes the element of threat $(0.354)$. In other word, although the hunting-familiar inmates just present a provocative behavior at superficial level (which can be triggered by incidental conditions), they present a considerably more aggressive profile (namely, enriched with threat) at idiosyncratic level.

Thus, hunting seems to be connected with a specific element of aggressiveness at the deeper (idiosyncratic) level and in combination with certain elements (namely, verbal and gestural harassment). Nevertheless, this particular (more aggressive) profile adopted by inmates who have experienced hunting, seems to remain independent of the tendency to harm (0.235 insign.). This result sup- 
ports the assumption that being a hunter is independent of being harmful due to idiosyncrasy. As for the idiosyncratic-induced threat which strengthens this profile, it could be regarded as an "overflowing" part of aggression which was transformed in hunting during their life outside prison. Hunting is an activity converting the aggression into a kind of sport which is harmless to human beings. This particular harmlessness is indicated in the insignificant coefficient (0.235).

In strategic behavioral patterns (Table 7), once again the hunting-unfamiliar and the hunting-familiar group present quite same profiles as in the case of the superficiality (Table 5) and idiosyncratic driving force (Table 6). Particularly, the three profiles, namely "sophisticated and harmful" $(0.459,0.643)$, "unsophisticated and harmful" $(0.894,0.663)$, "threatening and harmful" $(0.650,0.550)$, seem to be quite stable and could be characterized as trivial under incidental conditions (Table 5), impulsiveness (Table 6) and adaptiveness (Table 7). However, in the hunting-familiar group the extreme behavioral pattern of "fully 'dangerous"' may appear. All possible forms of aggressiveness measured in this research $(0.543,0.791,0.839,0.615)$ seem to converge under the necessity of adopting a strategic behavior depending on exogenous conditions and to indicate a susceptibility to extend the verbal aggressiveness to more harmful forms of aggressiveness (Sabourin, Infante \& Rudd, 1993). Such a profile which is strengthened with the parameter of harming in comparison with the respective profiles of Table 5 and Table 6 , seems to be connected with hunting-familiarity as a strategic behavior, as harming is, as a rule, the most extreme and risky reaction, regarded as a final option for surviving in any "hostile" environment. Such an extreme solution may reasonably be supposed to be the output of a strategic decision. Such a decidedness could be regarded as reflection of aggression, dominance or survival potential which may be externalized in hunting in free life (of course, this does not mean that hunting necessarily cultivates aggressiveness, but only that certain persons with such a deep-rooted potential may also use hunting as one of the several options they would have to release this potential/abreact). Simultaneously, such an "all-sided" aggressive reaction may be more easily decided by persons who were used to developing "all” (or several) skills, including also behavioral skills, in order to be as effective as possible in hunting.

Table 7. Strategic aggressiveness typology of inmates.

\begin{tabular}{|c|c|c|c|c|}
\hline & \multicolumn{2}{|c|}{ Hunting-familiar (=15 inmates) } & \multicolumn{2}{|c|}{ No hunting-familiar (=20 inmates) } \\
\hline & Fully"dangerous" & $\begin{array}{l}\text { Threatening and harmful } \\
\text { (implementing without announcing) }\end{array}$ & $\begin{array}{l}\text { Unsophisticated } \\
\text { and harmful }\end{array}$ & $\begin{array}{l}\text { Sophisticated } \\
\text { and harmful }\end{array}$ \\
\hline Strategic over-extrovert threat & 0.543 & 0.650 & 0.894 & 0.064 \\
\hline Strategic over-extrovert verbal harassment & 0.791 & -0.476 & 0.556 & -0.656 \\
\hline Strategic over-extrovert gestural harassment & 0.839 & -0.375 & -0.260 & 0.459 \\
\hline Strategic over-extrovert harming & 0.615 & 0.550 & 0.663 & 0.643 \\
\hline
\end{tabular}

Extraction method: Principal component analysis. 


\subsection{Summarizing and Concluding}

The criminal profile, as it can be described by in the common law terms (intention, violent character of crime, instrument used for committing it, severity, relapsing) seems hardly to be related with hunting experience or attitude. Various or severe criminal acts committed premeditatedly and with dangerous instruments (truncheon, axe, fire gun) is connected with illegal hunting in the framework of immanent and generalized tendency of deviant behavior (as expected, if someone has no hesitation of making injury or killing human being, he can easily kill an animal without being restricted by any written rule).

Committing crime by angriness seems to be connected with regarding hunting as a way of life (namely, a deep-rooted value system) in the light of romantic world view. The negative attitude of violent criminals toward hunting can be regarded as evidence of a human-oriented aggressiveness. Confining aggressive intention to human beings and not extending it to wild animals implies a tendency to maintain a hopeful side of "salvation" in this world. In other word, the particular findings (violent criminality and negative attitude toward hunting) are not contradictive but rather revealing an ability to separate the "(bad) real" from the "ideal" (or, at least, to maintain the hope that "ideal" can exist). Additionally, the irrelevance of relapsing and criminal severity for hunting experience or attitude shows the independence of hunting from any generalized deviant behavior leading to "unsocial" or "social-destructive" options of life.

The relation of hunting experience and attitude with the superficial, idiosyncratic and strategic aggressiveness was also examined. These three occasions of aggressiveness describe the incidental reaction, impulsive and adaptive reaction, respectively. The above-mentioned parameters of hunting are quite irrelevant to the incidental reaction, as accidental acts do not depend on any wider value system (part of which would also be any view of or interest in hunting). Only incidental harming seems to be indirectly relevant to hunting and angriness.

The impulsiveness seems to be more strongly correlated with hunting. People who are impulsively involved in threatening tend to keep out of further and unnecessary risks such as illegal hunting. Thus, in case of impulsive aggressiveness, this hunting-related behavior (not illegal hunting) shows at least precariousness, if not rationality and self-control.

Gestural harassment and hunting appear to be complementary ways of discharging aggressiveness. In other word, a noiseless way of expression (such as gesture) seems to need a complementary noisy way (like hunting).

Inmates being impulsively harmful seem to lack any deep consideration of hunting and they confine themselves in regarding merely as a "hobby". This is an indication that hunting maintains a deeper ethical-mental character, which differentiates it from a simple way of discharging aggressiveness. When hunting is deprived of this ethical-mental ("protective") consideration and is regarded as a mere "hobby", then it tends more easily to be connected with impulsive harmfulness.

In case of adaptiveness, there are many similarities with impulsiveness. How- 
ever, there is a characteristic difference: the gestural harassment appears to be independent of hunting. Namely, the "symbolic" and the "physical" way of discharging aggressiveness seem to be independent in case of adaptive aggression. Thereby, gestural harassment seems to be detectable mainly as impulsive and not as a strategic nor as an incidental reaction.

The typology which is based on the existence (or not) of hunting experience seems to be more insightful than the afore-mentioned correlation results derived from the whole sample, as it reveals a gradual involvement of aggressiveness dimensions, from incidentality to impulsiveness and further to adaptiveness in the group of inmates with hunting experience. In this group the following behavioral patterns of gradually enhanced aggressiveness appear: incidentally just provoking, impulsively being aggressive but without harming, and adaptively being aggressive and harming.

Being gradually more "dangerous" from the incidental to impulsive level and much more to the level of adaptiveness constitutes an escalation of aggressiveness which depicts a succession from the quite "accidental" (superficial) to the quite "planned" (adaptive). The impulsive action is more dependent on the decision of an inmate than incidental behavior but also not so planned, considering the exogenous conditions. Thus, such a decided action could be called "spontaneous", as it is based on a (behavioral) option of the inmate but still not on a (more meticulous) plan. Thus, having experience with hunting seems to be related with a sense of commensurability: "accidentally I only provoke", "spontaneously I dare also to threat but nothing more", and "I will harm when the conditions necessitate this-of course after planning". A supporter of hunting might characterize such commensurability as thoughtfulness. Furthermore, if he wanted to normatively stretch this supportiveness, he could characterize hunting as a "noble" activity for "thoughtful" people.

However, it should not be unnoticed that the trivial behavior of "implementing without announcing" may also appear in the hunting-familiar group, disregarding of the occasion (incidentality, impulsiveness or adaptiveness). This undifferentiated behavior might be attributed by a criticizer of hunting to a dogmatism which could be "expected" only from people who spend time such a "rough" and "violent" hobby like hunting.

Nevertheless, the group of inmates who have no relation to hunting tends to present undifferentiated behavioral patterns, namely being as a rule harmful either in a "sophisticated" or "unsophisticated" way. Thus, in general they might be characterized as more "inflexible", "stable" or "disregarding" particular occasions than hunting-familiar group.

\section{References}

[1] Anderson, C.M. and Martin, M.M. (1995) Why Employees Speak to Coworkers and Bosses: Motives, Gender, and Organizational Satisfaction. Journal of Business Communication, 32, 249-265. https://doi.org/10.1177/002194369503200303

[2] Bekiari, A. and Sakellariou, K. (2003) Perceived Instructor Verbal Aggressiveness and Student State Learning in Physical Education. Italian Journal of Sport Sciences, 
1, 251-256.

[3] Bekiari, A. and Manoli, P. (2016) EFL Teacher Verbal Aggressiveness and Argumentativeness and Student Socio-Affective Strategy Use and Affective Learning: Exploring Possible Associations. Journal of Teacher Education and Educators, 5, 154-171.

[4] Infante, D.A., Myers, S.A. and Buerkel, R.A. (1994) Argument and Verbal Aggression in Constructive and Destructive Family and Organizational Disagreements. Western Journal of Communication, 58, 73-84. https://doi.org/10.1080/10570319409374488

[5] Infante, D.A. and Rancer, A.S. (1996) Argumentativeness and Verbal Aggressiveness: A Review of Recent Theory and Research. Communication Yearbook, 19, 319 352.

[6] Infante, D.A. and Wigley III, C.J. (1986) Verbal Aggressiveness: An Interpersonal Model and Measure. Communications Monographs, 53, 61-69. https://doi.org/10.1080/03637758609376126

[7] Manoli, P. and Bekiari, A. (2015) EFL Teachers' Verbal Aggressiveness and Students' Intrinsic Motivation and Social-Affective Strategy Use: Investigating Possible Relations. Advances in Research, 5, 1-13. https://doi.org/10.9734/AIR/2015/19692

[8] Rancer, A.S. and Avtgis, T.A. (2014) Argumentative and Aggressive Communication. 2nd Edition, Peter Lang, New York.

[9] Bekiari, A. (2012) Perceptions of Instructors' Verbal Aggressiveness and Physical Education Students' Affective Learning. Perceptual and Motor Skills, 115, 325-335. https://doi.org/10.2466/06.11.16.PMS.115.4.325-335

[10] Bekiari, A. (2014) Verbal Aggressiveness and Leadership Style of Sport Instructors and Their Relationship with Athletes' Intrinsic Motivation. Creative Education, 5, 114-121. https://doi.org/10.4236/ce.2014.52018

[11] Bekiari, A. (2016) Insights into Instructors' Verbal Aggressiveness and Students' Machiavellianism through Leadership Style and Motivational Climate. European Scientific Journal, 12, 90-110. https://doi.org/10.19044/esj.2016.v12n25p90

[12] Bekiari, A., Kokaridas, D. and Sakellariou, K. (2005) Verbal Aggressiveness of Physical Education Teachers and Students' Self-Reports of Behavior. Psychological Reports, 96, 493-498. https://doi.org/10.2466/pr0.96.2.493-498

[13] Bekiari, A., Kokaridas, D. and Sakellariou, K. (2006) Associations of Students' SelfReport of Their Teacher's Verbal Aggression, Intrinsic Motivation, and Perceptions of Reasons for Discipline in Greek Physical Education Classes. Psychological Reports, 98, 451-461. https://doi.org/10.2466/pr0.98.2.451-461

[14] Bekiari, A. and Syrmpas, I. (2015) The Influence of Motivational Climate and Coaches' Verbal Aggression on Athletes' Satisfaction. British Journal of Education, Society \& Behavioural Science, 9, 318-329. https://doi.org/10.9734/BJESBS/2015/17757

[15] Bekiari, A. and Tsiana, I. (2016) Exploring Instructors' Verbal Aggressiveness and Students' Personal Orientations and Reasons of Discipline in Physical Education Class. Advances in Physical Education, 6, 158-168.

https://doi.org/10.4236/ape.2016.63018

[16] Claus, C.J., Chory, R.M. and Malachowski, C.C. (2011) The Relationship between Instructor Aggressive Communication Traits and Student Antisocial Behavioural Alteration Techniques. Paper Presented at the Annual Meeting of the Eastern Communication Association, Alexandria.

[17] Myers, S.A., Edwards, C., Wahl, S.T. and Martin, M.M. (2007) The Relationship 
between Perceived Instructor Aggressive Communication and College Student Involvement. Communication Education, 56, 495-508. https://doi.org/10.1080/03634520701466398

[18] Myers, S.A. and Rocca, K.A. (2001) Perceived Instructor Argumentativeness and Verbal Aggressiveness in the College Classroom: Effects on Student Perceptions of Climate, Apprehension, and State Motivation. Western Journal of Communication, 65, 113-137. https://doi.org/10.1080/10570310109374696

[19] Myers, S.A. and Knox, R.L. (1999) Verbal Aggression in the College Classroom: Perceived Instructor Use and Student Affective Learning. Communication Quarterly, 47, 33-45. https://doi.org/10.1080/01463379909370122

[20] Schrodt, P. (2003) Students' Appraisals of Instructors as a Function of Students' Perceptions of Instructors' Aggressive Communication. Communication Education, 52, 106-121. https://doi.org/10.1080/03634520302468

[21] Bekiari, A., Perkos, S. and Gerodimos, V. (2015) Verbal Aggression in Basketball: Perceived Coach Use and Athlete Intrinsic and Extrinsic Motivation. Journal of Physical Education and Sport, 15, 96-102.

[22] Bekiari, A., Digelidis, N. and Sakelariou, K. (2006) Perceived Verbal Aggressiveness of Coaches in Volleyball and Basketball: A Preliminary Study. Psychological Reports, 103, 526-530.

[23] Bekiari, A., Patsiaouras, A., Kokaridas, D. and Sakellariou, K. (2006) Verbal Aggressiveness and State Anxiety of Volleyball Players and Coaches. Psychological Reports, 99, 630-634.

[24] Hassandra, M., Bekiari, A. and Sakellariou, K. (2007) Physical Education Teacher's Verbal Aggression and Student's Fair Play Behaviors. The Physical Educator, 64, 94-101.

[25] Lemieux, P., McKelvie, S.J. and Stout, D. (2002) Self-Reported Hostile Aggression in Contact Athletes, No Contact Athletes and Non-Athletes. Athletic Insight, 4, 42-56.

[26] Mazer, J.P., Barnes, K., Grevious, A. and Boger, C. (2013) Coach Verbal Aggression: A Case Study Examining Effects on Athlete Motivation and Perceptions of Coach Credibility. International Journal of Sport Communication, 6, 203-213. https://doi.org/10.1123/ijsc.6.2.203

[27] Syrmpas, I. and Bekiari, A. (2015) The Relationship between Perceived Physical Education Teacher's Verbal Aggressiveness and Argumentativeness with Students' Interpersonal Attraction. Inquiries in Sport \& Physical Education, 13, 21-32.

[28] Sabourin, T.C., Infante, D.A. and Rudd, J.E. (1993) Verbal Aggression in Marriages A Comparison of Violent, Distressed but Nonviolent, and Nondistressed Couples. Human Communication Research, 20, 245-267. https://doi.org/10.1111/j.1468-2958.1993.tb00323.x

[29] Ding, C.S., Nelsen, E.A. and Lassonde, C.T. (2002) Correlates of Gun Involvement and Aggressiveness among Adolescents. Youth \& Society, 34, 195-213. https://doi.org/10.1177/004411802237863

[30] Wilkinson, D.L., McBryde, M.S., Williams, B., Bloom, S. and Bell, K. (2009) Peers and Gun Use among Urban Adolescent Males: An Examination of Social Embeddedness. Journal of Contemporary Criminal Justice, 25, 20-44. https://doi.org/10.1177/1043986208328449

[31] Sipes, R.G. (1973) War, Sports and Aggression: An Empirical Test of Two Rival Theories. American Anthropologist, 75, 64-86. https://doi.org/10.1525/aa.1973.75.1.02a00040

[32] Bartholow, B.D., Anderson, C.A., Carnagey, N.L. and Benjamin, A.J. (2005) Interac- 
tive Effects of Life Experience and Situational Cues on Aggression: The Weapons Priming Effect in Hunters and Nonhunters. Journal of Experimental Social Psychology, 41, 48-60. https://doi.org/10.1016/j.jesp.2004.05.005

[33] Kuentzel, W.F. and Heberleln, T.A. (1998) Why Do Hunters Skybust? Personal Disposition or Social Influence. Human Dimensions of Wildlife, 3, 1-15. https://doi.org/10.1080/10871209809359111

[34] Bekiari, A. and Hasanagas, N. (2015) Verbal Aggressiveness Exploration through Complete Social Network Analysis: Using Physical Education Students' Class as an Illustration. International Journal of Social Science Studies, 3, 30-49. https://doi.org/10.11114/ijsss.v3i3.729

[35] Bekiari, A., Hasanagas, N., Theoharis, D., Kefalas, I. and Vasilou, A. (2015) The Role of Mathematical Object and the Educational Environment to Students' Interpersonal Relationships: An Application of Full Social Network Analysis. Proceedings of the 32nd Congress Greek Mathematical Society, Kastoria, 28 October-1 November 2015, 799-812.

[36] Bekiari, A. and Spyropoulou, S. (2016) Exploration of Verbal Aggressiveness and Interpersonal Attraction through Social Network Analysis: Using University Physical Education Class as an Illustration. Open Journal of Social Sciences, 4, 145-155. https://doi.org/10.4236/jss.2016.46016

[37] Hasanagas, N. and Bekiari, A. (2015) Depicting Determinants and Effects of Intimacy and Verbal Aggressiveness Target through Social Network Analysis. Sociology Mind, 5, 162-175. https://doi.org/10.4236/sm.2015.53015

[38] Theoharis, D. and Bekiari, A. (2016) The Influence of Mathematics and Learning Environment in Verbal Aggressiveness and Interpersonal Relations: A Dynamic Analysis of Social Networks. 8th International Congress Mathematical Society, Thessaloniki, 30 March-3 April 2016, 145-155 (orig. in Greek).

[39] Theoharis, D. and Bekiari, A. (2016) Analyzing Centrality Indicators of Social Networks. Case Study on Leadership Networks of Students and Teachers. Proceedings of the 33rd Congress of Greek Mathematical Society, Chania, 4-6 November 2016, 250-260.

[40] Theoharis, D., Bekiari, A. and Koustelios, A. (2017) Exploration of Determinants of Verbal Aggressiveness and Leadership through Network Analysis and Conventional Statistics. Using School Class as an Illustration. Sociology Mind. (Forthcoming)

[41] Bekiari, A. and Hasanagas, N. (2016) Suggesting Indicators of Superficiality and Purity in Verbal Aggressiveness. An Application in Adult Education Class Networks of Prisoners. Open Journal of Social Sciences, 4, 279-292. https://doi.org/10.4236/jss.2016.43035

[42] Bekiari, A. and Digelidis, N. (2015) Measuring Verbal Aggressiveness in Sport and Education. International Journal of Physical Education, 4, 12-21.

[43] Popitz, H. (1992) Phänomene der Macht. 2. Stark erweiterte Auflage. Tübingen.

[44] Bekiari, A. and Hasanagas, N. (2016) Sociological Insights in the Education System: "Unlocking" the Power Relations. Afoi Kyriakidi Editions S.A., Thessaloniki.

[45] Bekiari, A. and Hasanagas, N. (2016) "Educating" in Physical Education. Theoretical Approaches and Practical Inquiries. Afoi Kyriakidi Editions S.A., Thessaloniki.

[46] Lowenfeld, H. (1969) Human Aggression: By Anthony Storr. New York: Atheneum Publishers, 1968. 127 p. Psychoanalytic Quarterly, 38, 491-494.

[47] Hasanagas, N., Birtsas, P. and Sokos, C. (2011) The Hunting as Way of Life, as Sport and as Hobby. 15th Pan-hellenic Forest Science Conference, Hellenic Forestry Association, Karditsa, 16-19 October 2011, 1-13 (orig. in Greek). 
Submit or recommend next manuscript to SCIRP and we will provide best service for you:

Accepting pre-submission inquiries through Email, Facebook, LinkedIn, Twitter, etc. A wide selection of journals (inclusive of 9 subjects, more than 200 journals)

Providing 24-hour high-quality service

User-friendly online submission system

Fair and swift peer-review system

Efficient typesetting and proofreading procedure

Display of the result of downloads and visits, as well as the number of cited articles Maximum dissemination of your research work

Submit your manuscript at: http://papersubmission.scirp.org/

Or contact $\underline{\text { sn@scirp.org }}$ 